\title{
Information, Resources and Transaction Cost Economics: The Effects of Informal Network Centrality on Teams and Team Performance
}

\author{
William C. McDowell \\ East Carolina University \\ Troy A. Voelker \\ University of Tennessee at Martin
}

\begin{abstract}
This study presents a theoretical framework for studying the effects of extra-group social networks on teams. Building on a transaction cost economics framework, an individual's extra-group friendship network centrality is proposed to relate to communication network centrality. This is because the individual will utilize the network to establish an informational hierarchy thereby reducing the transaction costs associated with finding information and resources. Through this network the individual will be perceived as a higher team contributor. The team effects of extra-group network centrality are proposed as higher team performance and innovativeness. Future research opportunities and implications for practical use are presented.
\end{abstract}

\section{Introduction}

The study of teams and collaborative systems within organizations continues to uncover multiple layers of team dynamics. These dynamics need to be understood in an effort to create more innovative and successful organizations. Guzzo and Dickson (1996) highlight many aspects of teams that heighten productivity such as cohesiveness, composition, leadership, motivation and more, but the study of teams goes well beyond the organizational behavior constructs that have been the focus of so much attention. Social networks, which have been studied for some time, have received new attention in team literature. Social network studies have looked at social conflict (Labeianca, Brass, \& Gray, 1998), team communication (Brown \& Miller, 2000), team coordination (Lazer \& Katz, 2000), structural properties (Cummings \& Cross, 2003) and other aspects of team work.

One area which has not received sufficient attention, however, is the role of social networks and team performance. When teams are examined, there is centrality within the team itself. This within-team centrality has implications for individual performance, satisfaction, and other individual level outcomes (Mehra, Kilduff, \& Brass, 2001; Ibarra, 1993; Ibarra \& Andrews, 1993). However, by looking outside of the team and into the informal structure of the organization or system, centrality beyond the formal team, or extra-group centrality, should have influential implications for the individual and the formal team. Reagans, Zuckerman, and McEvily (2004) did find that organizations could reduce costs and increase performance by managing this network that lies outside the team but within the organization. They found that the diversity available through individuals with extensive outside networks is predictive of team performance. 
Similarly, Tsai (2001) demonstrated that in-degree centrality of teams within organizations was positively related to the innovativeness of those teams. These studies provide some clear indication that the intra-organizational social capital of teams plays an important, yet under-studied role, role in the performance of teams within organizations. With a better understanding of the implications of the informal network structure of the organization on the performance of structured teams, work process designs may be better developed to capitalize on these advantages. One way to understand this influence of the informal network structure is through transaction cost economics.

Transaction cost economics (TCE) has historically played an important role in determining if an organization is formed to complete transactions within the marketplace or within hierarchy (Williamson, 1975). Further, the social relationship that is chosen based on the friction of exchange, or costs, may influence a direction of business for the firm toward either the market or the use of hierarchy (Granovetter, 1985). This friction of exchange that takes place within the market leads to the establishing of hierarchies, the internalization of the processes rather than relying on the market, to realize greater economies and hopefully higher profit. And, while TCE has primarily been utilized when explaining the structuring of organizations in relation to the market, it seems reasonable to apply it to the exchanges of information and resources that must take place between the team and the larger organization. The reasoning for this is that rather than relying solely on an inefficient market, external research or information seeking, an individual will utilize the informal network as a source of important and late-breaking information.

This paper explores how individual centrality outside of the formal team and into the informal structure of an organization leads to more efficient information gathering for the individual and higher performance and innovativeness for the team. To accomplish this, centrality, extra-group centrality, and transaction cost economics will be examined and integrated into a social networks model. This model will be a framework for greater understanding of the use of the informal network for individual and team effectiveness.

Figure 1. An integrated model of extra-group centrality on network types, contribution, team performance and team innovativeness

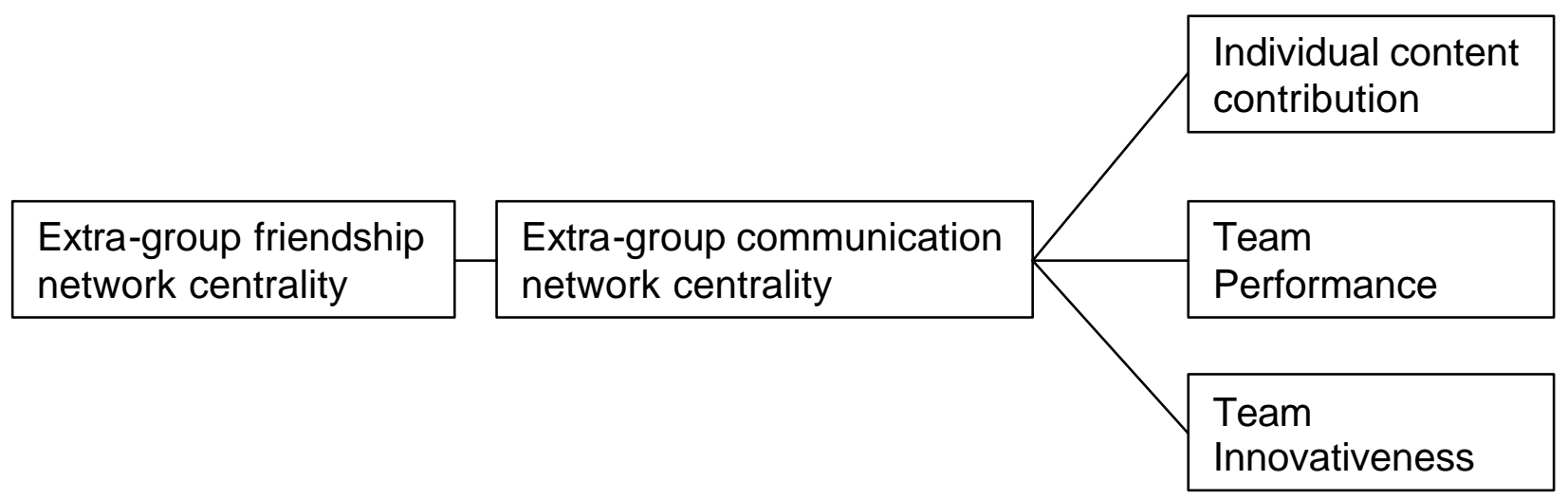




\section{Transaction Cost Economics}

Transaction cost economics (TCE) was first introduced in a paper by Coase (1937) in which he attempted to explain why organizations exist. Williamson (1975) built on this theory and developed the current framework for understanding the role of TCE in organizations. The premise of TCE is that individuals, in an imperfect market, will utilize hierarchy rather than the market to reduce the friction of exchange, which can better be described as transaction costs.

There are two human elements of TCE that Williamson introduces which are vital to the understanding of TCE. The first, bounded rationality, means that "the rationality of human behavior is limited by the ability of actors to process information; agents are intendedly rational, but only limitedly so" (Jones, 2001, 211)." Opportunism, the second human element, can be defined as "the rational pursuit by economic actors of their own advantage, with all means at their command, including guile and deceit" (Granovetter, 1985, p. 494).

A team within an organization seeking innovation needs a variety of information and resources in order to achieve these goals. Rarely will a team be put together which has all of the necessary individuals, information and resources already within the team, but within the organization may exist these vital components necessary for the team to be highly innovative. The organization outside of the team represents what TCE would call the market. While the information within this market exists, it is difficult to obtain or the costs associated with obtaining it may be high. Under these circumstances, TCE argues that the team will establish a hierarchy, or extend into the rest of the organization and incorporate into the team individuals who possess this necessary information, thus minimizing the friction of exchange to obtain this information.

Pulling others into the team may seem to be a viable solution initially, but the information necessary to be innovative or high producing may be more tacit than explicit. More specifically, the team may not know exactly what information or resources are necessary, or available, a priori. So, there are two major problems. First, as mentioned before, the friction of exchange to pull the information from the rest of the organization may be difficult and costly depending on the costs associated with this type of information gathering. Second, since the information or social capital is more tacit than explicit, how can a team know whom to choose to bring within the formal team? Also, there are forces beyond the team limiting the ability to bring others into the team and developing this hierarchy. So, both the market and traditional hierarchy are inefficient and unproductive ways to develop this system.

An alternative to this is through the use of a social network tool of centrality. A pseudohierarchy can be established in which an individual within the team brings in the knowledge of others with a limited amount of friction of exchange. Rather than attempting to retrieve the necessary information and resources from just random individuals and rather than attempting to bring every potential contributor into the team, an individual can bring into a pseudo-hierarchy those individuals within the organization 
who may have the necessary social capital for greater innovation and production. This is done not by inserting those others into the team, but by the team member embedding himself or herself into the flow of information within this network. By embedding oneself, this individual can determine what information does exist and from whom to retrieve it. An examination of network centrality assists in understanding this pseudohierarchy.

\section{Centrality}

Network centrality is an important element in the study of social networks because of the implications of information exchange within organizations. Centrality within a social network implies connectedness to others within an organization. Degenne and Forse (1999) indicate that there are three types of centrality. First, degree centrality, the simplest form, denotes only the number of connections to others in the network. Second, closeness centrality, as the label implies, measures more than just the number of connections and looks at the closeness of the individual to the others. The third, betweenness centrality, is more specific in determining the level of intermediary support of information to the others. Borgatti (2005) also provides a useful discussion of these three approaches to measuring centrality and demonstrates how the specific measures of centrality reflect different conceptions of information flow within networks. Our study uses these ideas in our discussion of different types of exchange networks within organizations, for our purposes we focus on friendship and communication networks.

When examining centrality and the effects it has for individuals and teams, network centrality within an organization implies a greater degree of access to information and resources (Ibarra, 1993; Burt, 1992). This is why centrality is so heavily related to the issue of power (Ibarra, 1993). A great deal of research has been done on determining whether various levels of centrality are equally as advantageous to the individual.

Centrality includes both strong ties and weak ties associated with the information gained through this social network. Some of the most important information concerning the advantages of centrality has come from the work concerning the usefulness of weak ties (Granovetter, 1973; Hansen, 1999). What has arisen from this stream of research is that in many cases some of the most innovative and important information can come from these weak ties. Granovetter (1973) defines a weak tie as one that is distant or infrequent. This has powerful implications for the use of social networks within organizations, because many times these weak ties prove most useful for performance. Transaction cost economics and the development of the pseudo-hierarchy can harness these weak ties for the team's benefit.

While understanding network centrality is important, another addition is that without the insertion of social capital, the networks are not useful. Social capital is the information or resources that come from the others in the social network. Burt (1992), when expressing the importance of social capital to organizations, states that social capital determines whether an organization or an individual will be competitive or not. In an imperfect world with uncertainties in every direction, social capital becomes even more 
important. Utilizing this social capital gives the individual a greater degree of power and ability to perform (Sparrow, Liden, Wayne \& Kraimer, 2001). Greater levels of centrality create benefits and opportunities that are unavailable to those less central within the organization (Ibarra \& Andrews, 1993). These higher levels of centrality indicate greater pseudo-hierarchies that are developed to enhance the effectiveness of information gathering within the team.

\section{Friendship and Communication Networks}

Centrality within an organization assumes that relationships exist. Two types of relationships that are important to study when looking at organizations are friendship networks and communication networks. Friendship networks imply basically a network where friends are indicated by the central person. These are acquaintances for social purposes that are used for enjoyment in a variety of situations (Baldwin, Bedell, \& Johnson, 1997).

Another network for individuals within organizations is communication networks. Communication networks go beyond friendship networks and imply that information necessary for job performance or information exchange passes through individuals within this network (Rogers, 1979). This social capital received from other individuals can be vital to the team or organization. It is also noted that the centralized person, or the individual through whom this information is relayed, is at the top of the hierarchical structure (Brown \& Miller, 2000). In the case of centrality of an individual within the team, the hierarchical structure here would be the pseudo-hierarchical structure.

By utilizing this understanding, and the understanding of TCE, it is proposed that an individual with a high degree of network centrality outside of the formal team setting and into the informal network system will utilize the friendship network as a communication network in situations of uncertainty. In other words, because of the friction of exchange in researching and learning the intricacies of a project, the highly centralized person will develop a social communication network from the friendship network. This is like establishing a TCE hierarchy instead of utilizing a market type relationship but using information as the unit exchanged rather than goods or services. Rather than relying solely on research and outside learning, the individual will build these relationships into an informational hierarchy for personal use. The hierarchy is a greater system for transferring information (Granovetter, 1985). Therefore, the first proposition takes this into account.

Proposition 1: Individual extra-group friendship network centrality will be positively related to individual communication network centrality.

\section{Individual Information Contribution}

In addition to the above proposition, because of the individual's position of centrality within this communication network, they will be the focus of a great deal of information and resources from the communication network. Therefore, more information will be 
available to them than others in the team (Brown \& Miller, 2000). Previous research has shown that this centrality within networks is associated with higher levels of individual performance (Baldwin et al., 1997; Sparrow, Liden, Wayne, \& Krammer, 2001).

This centralized person, who establishes the network or hierarchy of information through others, will utilize these relationships and emerge as a dominant contributor of information to the rest of the team. The individual receives the information and resources from the hierarchical structure of the information network and relays this information to the team. While no social capital may have been developed, it has been taken from others and presented to the team (Nahapiet \& Ghoshal, 1998).

Therefore, it is proposed, through the framework of TCE, that in the network relationships, individuals with a greater degree of extra-group centrality will be perceived by team members as a high content contributor to the team project. This can be seen by examining the level of communication networks with content contribution.

Proposition 2: Individual extra-group communication network centrality will be positively related to content contribution perceptions of other team members.

\section{Team Performance and Innovativeness}

To further this examination of the effects of centrality, it is valuable to turn to team performance and team innovativeness. Guzzo and Dickson's (1996) summary of antecedents to team performance include cohesion, heterogeneity, familiarity, motivation, communication and more. Other factors such as individual creativity (Tagger, 2002), self-efficacy (Tierney \& Farmer, 2002; Earley, 1994), potency (Tesluk \& Mathieu, 1999) and member expertise (Bonner, Baumann \& Dalal, 2002) have also been suggested to determine team performance.

When we look at the issue of member expertise (Bonner et al, 2002), it is noticed that teams with members who are considered experts outperform others with less expertise when team processes are held constant. The issue of expertise is generally associated with greater levels of information or understanding of the situation at hand. It could be related to past performance as the authors indicate, or it could simply be an outcome of previous experience.

A general proposition arising from this discussion is that a centralized individual will bring to the team a great deal of information, which in turn will result in higher team performance. Again, based on TCE and the use of the hierarchical structure as a source of information rather than the use of the open market or just the team itself, the highly centralized individual in the communication network will utilize this network as a source of information and resources, thereby gaining information more quickly and efficiently (Granovetter, 1985) that will result in higher team performance. 
However, two previous studies found some conflicting results. Ancona (1990), in a study of cross functional teams, found that boundary spanning between teams resulted in higher levels of team performance. This seems intuitive, but in a study by Baldwin et al. (1997) the relationship between centrality and team grade was not significant. He even noticed a negative relationship between friendship expansiveness and team grade. The reason for this divergent finding was attributed to the differences between the two types of teams studied, actual project teams in industry verses classroom teams of students. As teams are formed for differing purposes, the role of centrality in the performance of teams may vary enhancing the need to improve our understanding of teams to organization network processes.

There does seem to be, however, a positive relationship between the communication network centrality and team performance. The reason for this is because of the pseudo-hierarchical structure that is facilitated by the highly centralized person. The Baldwin et al. (1997) piece indicated that the friendship and communication network relationships are formed mostly within the formally assigned teams. The proposition this paper makes is that when the centrality of the formally structured team is excluded from the analysis and only the extra-group level of centrality is examined, the higher levels of communication network centrality of individuals will be positively related to team performance. Greater levels of information and resources will be available to the team through the individual that will aid the team in performance.

An explanation for the utility of extra-group centrality influencing team performance can be found in the work of Thomas et al (1993). In this experiment, the authors examined the information scanning heuristics of upper managers as an antecedent to adaptive behaviors, innovations, and long term performance. CEO's who utilized more sources of information scanning in an analysis were found, over time, to also engage in more positive adaptations to fluctuating markets. The conclusion drawn from Thomas et al (1993) therefore, is that utilization of information positively relates to performance by way of adaptation. For purposes of our proposition, extra-group network centrality as a conduit for information accumulation increases the ability of the team to anticipate and enact appropriate decisions thus leading to superior long -term performance. Therefore, the following proposition is introduced.

Proposition 3: Individual extra-group communication network centrality is positively related to team performance.

\section{Team Innovativeness}

Transitioning from team performance to team innovativeness, much of the same argument applies. Amabile et al. (1996) defines innovativeness within a team as the successful implementation of innovative ideas. Therefore, looking at innovativeness within teams, innovativeness is creatively assessing the team problem or task and utilizing innovative ideas to develop an innovative and useful solution. The authors go on to state that the inception of innovations is with creative ideas. These ideas must 
either be developed or borrowed. Tagger (2002) emphasizes that an individual's role in contributing to innovativeness is through behaviors that support innovation.

Applying the extra-group communication network centrality to this situation, there are sources outside of the team for this individual to learn from and even borrow creative ideas. Baldwin et al. (1997) state that centrality can also help in receiving late-breaking information. Further, at the organizational level, firm centrality directly influences the innovativeness for firms (Ahuja, 2000). Recognizing that firm to firm relations require interaction of individuals and, further, as network processes frequently function similarly at the organizational, group and individual levels of analysis, it is reasonable to assume that extra-group centrality will influence the innovativeness of a team at the intraorganizational level (Brass, 1995). Therefore, because an individual will utilize the communication network as a source of information by establishing a type of hierarchical structure rather than depending on the organization market or the information within the team itself, it is proposed that the team will be the beneficiary of this information and will ultimately be viewed a more highly innovative team. The following proposal emphasizes this proposition.

Proposition 4: Individual extra-group communication network centrality is positively related to team innovativeness.

\section{Discussion and Implications}

The purpose of this paper is to develop a framework for the effects of extra-group centrality networks on team performance and innovativeness. In doing so, we examine friendship networks and how a team member will attempt to reduce the friction of exchange for obtaining information by developing an informational organization of hierarchy from which to pull ideas, information, and resources.

In addition, by creating this informational organization, this team member will establish him/herself as a primary information content provider to the team, which will be evident in the perceptions of that member by the others in the team. The paper also examined how these higher levels of centrality lead to greater team performance and team innovativeness because of the richer and greater volume of information that will be available to the team. Each of these items are summarized in visual form in Figure 1.

In organizations that are team based or utilize teams in the business process, performance is the ultimate goal. This performance may come in the outcome of higher profitability, greater output, greater efficiency, or even higher levels of innovativeness (Daft, 1995; Mohrman \& Mohrman, 1996). These teams offer a platform for higher performance in organizations. Teams allow for low hierarchical structures for decision making and they allow for a diversity of ideas from the team members that can enhance decision making and thus increase productivity and creativity (Sundstrom, 1999). Whatever the preferred outcome may be, in many instances teams are the direction that many top managers feel the company should go. Osterman (1994), in his study on organizational transformation, found that over $50 \%$ of the organizations that were 
sampled utilized teams in their organization. The study indicated that the development of teams is one of the most used areas of workplace transformation that management considers and uses. This proliferation of teams in organizations indicates the importance that upper management places on teams. The preferred outcomes may vary from organization to organization, but the usefulness and value that teams in organizations can offer continues to increase.

But, it is necessary to understand what may help some teams to be more effective than others. The information outside of the formal team may not be easily recognizable as valuable, so this tacit information may be difficult to obtain through normal market type procedures. There is a great deal of uncertainty as to who may provide the best solutions therefore bringing an individual into the hierarchy of the team may end up being unprofitable. Since this uncertainty of what information is available and what is needed exists, setting an exchange relationship can be quite challenging. Therefore, through the setting up of a pseudo-hierarchy by means of the relationships through centrality, these ties, both strong and weak, can be of benefit to the team.

While the purpose of this paper is to outline how transaction cost economics offers explanatory mechanisms for the importance and impact of extra-group centrality on team performance, there are issues pertaining to the testing of these propositions. Specifically, we focus on issues relating to the measurement, level of analysis and technical issues of analysis implicit with examination of this phenomenon. As Reagans et al. (2004) indicate, it has been difficult until recently to collect, measure and test network data. Using network analysis, however, this data can be gathered within team based organizations and analyzed through a network analysis. Survey data can be used to capture the extra-group friendship and communication network centrality as well as the evaluations of individual content contribution. In addition, there are currently many options available for data on team performance or innovation. While this data may be time consuming to obtain, the potential for this data collection looks promising.

Level of analysis becomes inherently difficult in our propositions, a fact not uncommon in network analysis. In our model in figure one, two distinct levels appear. Extra-group centrality in the friendship and communication network and individual contribution are each individual level phenomenon. Team performance and team innovativeness are group level functions though. Network analysis is inherently multi-level, understanding and untangling social capital necessitates embracing multi-level examination (Borgatti and Foster, 2003). In addition to these individual and group level measures, the nature of individuals and teams play out within the larger context of the organization (recall that the network in our discussion is the organization itself), implying that network effects may play a role beyond our initial propositions. Our suggestions are in line with emerging calls for more multi-level research in organizational phenomenon (Hagedoorn, 2006; Parkhe, Wasserman, \& Ralston, 2006). Thus, while level is an important element to consider in addressing our propositions, promising suggestions for enacting this research stream have begun to appear. 
Finally, in the eventual testing of our propositions, methods of analysis itself present a non-trivial challenge. Network data is inherently interdependent and inter-correlated, substantially violating assumptions of traditional parametric analysis techniques. As with issues of measurement and level though, promising work and progress exists offering analysis alternatives which permit examination and testing of our hypothesis. Specifically, Dekker and colleagues offer the MRQAP regression technique as an analysis method robust to the various parametric violations inherent in network data (Dekker, Franses, \& Krackhardt, 2003). Additionally, Contractor and colleagues have recently offered an assessment of more common non-parametric techniques and provide guidelines for appropriate introduction and testing of multi-level propositions such as ours (Contractor, Wasserman, \& Faust, 2006). Thus, while measurement, level of analysis and method of analysis present interesting challenges to the study of our propositions, clear and emerging guidelines exist providing a starting point for empirical investigation. The time is therefore ripe for the study of extra-group network phenomenon.

This framework for understanding this alternative to a traditional hierarchy or utilization of the organization as the market can be very beneficial. Many organizations develop teams without regard for the informal networks that exist. Therefore, this stream of research should continue.

Future research involving social networks and the impact on team performance should include how to determine initial team membership, understanding how extra-group networks are initialized and how they may be maintained. This will serve to guide practitioners who see the benefit for teams within the organization. Also, it will give some direction for fostering the type of culture that is conducive to extra-group social networks.

Another direction for research in this area includes understanding how network centrality affects the organizational behavior of individuals within the teams. There is already literature on how centrality enables satisfaction (e.g. Baldwin et al., 1997) but what about issues such as self-efficacy, potency, and motivation? All of these characteristics may be greatly affected by network centrality.

One more area that could use future research is the effects of an individual's network centrality on the other members of the team. This study looked at how it may affect the perceptions of team involvement or contribution, but other areas of great importance could also be examined. In addition, while this study looked at the centrality of one team member, there must be some cumulative effect of the centrality of all the members of the team. The cumulative centrality scores may prove to be important for understanding outcomes. Relatedly, should the testing of our propositions evidence support, additional issues involving the resource assignment criteria of team members. Should our propositions find support, practitioners will be well served to consider the extra-group centrality of potential team members when choosing team formation. This will raise an addition question, beyond the scope of this initial offering as to whether increasing overlap in the extra-group centrality (by way of increasing the pseudo- 
hierarchy) or increasing the non-redundancy (by way of increasing the breadth of the search capability net) yields the best team-staffing rubric. Alternately, and perhaps more interestingly, which conditions potentially lead to each of the prior examples generating the better outcomes?

A limitation to this current study is the lack of understanding concerning how these centrality issues may change over time and under what conditions various levels may occur. For example, Baldwin et al. (1997) used MBA teams existing for two years. The results concerning performance were non-significant while Ancona (1990) had a much different type of study with positive results concerning a cross functional team working within an organization. The mixed results led to the reexamination in this paper with more certainty concerning the level of centrality, but how might various conditions cause results to differ.

Overall, this paper contributes to the current literature by examining through the lens of TCE the effect of extra-group friendship network centrality on communication networks. Also, the effects on the team perceptions of this centralized individual are examined. In addition, by discounting the centrality level in the structured team, this study examines what other studies have not by looking at the extra-group centrality effect on group performance and innovativeness. We feel the extra-group centrality of teams represents intriguing, challenging and ultimately rewarding area for future inquiry. We believe that our use of TCE and pseudo-hierarchy as an explanatory mechanism broadens and enriches the emergent research on teams within organizations. To that end, it is our hope that this paper serves as a catalyst for future research and development concerning network centrality utilizing TCE as a basis for this understanding.

\section{References}

Ahuja, G. (2000). Collaboration networks, structural holes, and innovation: A longitudinal study. Administrative Science Quarterly, 45, 425-???.

Amabile, T.M., Conti, R., Coon, H., Lazenby, J. \& Herron, M. (1996). Assessing the work environment for creativity. Academy of Management Journal, 39, 11541184.

Ancona, S. G. (1990). Outward bound: Strategies for team survival in an organization. Academy of Management Journal, 33, 334-365.

Baldwin, T. T., Bedell, M. D., \& Johnson, J. L. (1997). The social fabric of a team-based M.B.A. program: Network effects on student satisfaction and performance. Academy of Management Journal, 40, 1369-1397.

Bonner, B. L., Baumann, M. R., \& Dalal, R. S. (2002). The effects of member expertise on group decision-making and performance. Organizational Behavior and Human Decision Process, 88, 719-736. 
Borgatti, S. P. (2005). Centrality and network flow. Social Networks, 27(1), 55-71.

Borgatti, S. P., \& Foster, P. C. (2003). The network paradigm in organizational research: A review and typology. Journal of Management, 29(6), 991.

Brass, D. J. (1995). A social network perspective on human resources management. In G. R. Ferris (Ed.), Research in Personnel and Human Resources Management (pp. 39-79). Greenwich: JAI Press.

Brown, T. M., \& Miller, C. E. (2000). Communication networks in task-performing groups: effects of task complexity, time pressure, and interpersonal dominance. Small Group Research, 31, 131-157.

Burt, R.S. (1992). Structural holes: The social structure of competition. Cambridge, MA: Harvard University Press.

Coase, R.H. (1937). The nature of the firm. Economica, 4, 386-405.

Contractor, N., Wasserman, S., \& Faust, K. (2006). Testing multitheoretical, multilevel hypothesis about organizational networks: An analytic framework and empirical example. Academy of Management Review, 31, 681-703.

Cummings, J. N., \& Cross, R. (2003). Structural properties of work groups and their consequences for performance. Social Networks, 25, 197-210.

Daft, R.L. (1995). Organization Theory and Design ( $5^{\text {th }}$ Edition). Minneapolis/St. Paul: West.

Degenne, A. \& Forse, M. (1999). Introducing social networks. Thousand Oaks, CA: Sage Publications.

Dekker, D., Franses, P. H., \& Krackhardt, D. (2003). An equilibrium -correction model for dynamic network data. Journal of Mathematical Sociology, 27, 193-215.

Granovetter, M.S. (1973). The strength of weak ties. American Journal of Sociology, $78,1360-1380$.

Granovetter, M. (1985). Economic action and social structure: The problem of embeddedness. American Journal of Sociology, 91, 481-510.

Guzzo, R. A., \& Dickson, M. W. (1996). Teams in organizations: Recent research on performance and effectiveness. Annual Review Psychology, 47, 307-338.

Hagedoorn, J. (2006). Understanding the cross-level embeddedness of interfirm partnership formation. The Academy of Management Review, 31, 670. 
Hansen, M. T. (1999). The search-transfer problem: The role of weak ties in sharing knowledge across organization subunits. Administrative Science Quarterly, 44, $82-111$.

Ibarra, H. (1993). Network centrality, power, and innovation involvement: Determinants of technical and administrative roles. Academy of Management Journal, 36, 471501.

Ibarra, H., \& Andrews, S. B. (1993). Power, social influence, and sense making: Effects of network centrality and proximity on employee perceptions. Administrative Science Quarterly, 38, 277-303.

Jones, G.R. (2001). Towards a positive interpretation of transaction cost theory: The central roles of entrepreneurship and trust. In M.A. Hitt, R.E. Freeman, and J.S. Harrison, (eds.), Handbook of Strategic Management (pp. 208-228). Malden, MA: Blackwell Publishers, Inc.

Labianca, G., Brass, D. J., \& Gray, B. (1998). Social networks and perceptions of intergroup conflict: the role of negative relationships and third parties. Academy of Management Journal, 41, 55-67.

Lazer, D. \& Katz, N. (2000). Putting the network into teamwork. Academy of Management Conference. Assuming that this a paper presented at a conference, it needs to be rewritten thusly: Paper presented to the annual conference of the Academy of Management Conference, town, state.

Mehra, A., Kilduff, M., \& Brass, D. J. (2001). The social networks of high and low selfmonitors: Implications for workplace performance. Administrative Science Quarterly, 46, 121-146.

Mohrman, A.M. \& Morhman, S.A. (1996). Fundamental organizational change as organizational learning: Creating team-based organizations. Research in Organizational Change and Development, 10, 197-228.

Nahapiet, J., \& Ghoshal, S. (1998). Social capital, intellectual capital, and the organizational advantage. Academy of Management Journal, 23, 242-266.

Osterman, P. (1994). How common is workplace transformation and who adopts it? Industrial and Labor Relations Review 47, 173-188.

Parkhe, A., Wasserman, S., \& Ralston, D. A. (2006). New frontiers in network theory development. The Academy of Management Review, 31, 560. 
Reagans, R., Zuckerman, E, \& McEvily, B. (2004). How to make the team: Social network vs. demography as criteria for designing effective teams. Administrative Science Quarterly, 49, 101-133.

Rogers, E.M. (1979). Network analysis and the diffusion of innovation. In P.W. Holland and S. Leinhardt (eds.), Perspectives on Social Network Research, (pp. 137-164). New York: Academic Press.

Sparrow, R. T., Liden, R. C., Wayne, S. J., \& Kraimer, M. L. (2001). Social networks and the performance of individuals and groups. Academy of Management Journal, $44,316-325$.

Sundstrom, E.D. (1999). Supporting work team effectiveness: Best management practices for fostering high performance. San Fracisco, CA: Jossey-Bass.

Tagger, S. (2002). Individual creativity and group ability to utilize individual creative resources: A multilevel model. Academy of Management Journal, 45, 315-330.

Tesluk, J.R. \& Mathieu, J.E. (1999). Overcoming roadblocks to effectiveness: Incorporating management performance barriers into models of work group effectiveness. Journal of Applied Psychology, 84, 200-217.

Thomas, J. B., Clark, S. M., \& Gioia, D. A. (1993). Strategic sensemaking and organizational performance: Linkages among scanning, interpretation, action, and outcomes. Academy of Management Journal, 36, 239.

Tierney, P., \& Farmer, S.M. (2002). Creative self-efficacy: Its potential antecedents and relationships to creative performance. Academy of Management Journal, $45,1137-1148$.

Tsai, W. (2001). Knowledge transfer in intraorganizational networks: Effects of network position and absorptive capacity on business unit innovation and performance. Academy of Management Journal, 44, 996-1004.

Williamson, O. (1975). Markets and hierarchies. New York: Free Press. 